\title{
Motivations for the Adoption of Chronic Disease Information Systems in General Practice
}

\author{
Daniel Carbone \\ University of Melbourne, Australia \\ Stephen Burgess \\ Victoria University, Australia
}

\begin{abstract}
The purpose of this paper is to highlight the key motivational factors that lead to the successful implementation of Chronic Diseases Information Systems (CDISs) in twenty eight general practices in a case study of a large general practice division network in Australia. The literature identified three major areas of CDIS motivation: patient care gap motivator, internal motivators and external motivators. Patient care emerged as the most important motivation for adopting CDIS, followed by risk management and financial incentives. However, the study also determined that the motivational forces are inter-related and suggests that the decision to adopt CDIS should consider a number of these identified factors.
\end{abstract}

\section{Keywords}

Health Information Systems, Motivational factors, Chronic Diseases, Primary Care, Socio-technical theory,

\section{Introduction}

Chronic diseases (CDs) such as cancer and cardio-vascular, diabetic and respiratory conditions are by far the leading cause of mortality in the world and represent $60 \%$ of all deaths. Out of the 35 million people who died from chronic disease in 2005, half were under 70 and half were women. Furthermore, 338 million people are expected to die of chronic conditions over the next ten years [1-3].

According to the Word Health Organisation, many of these diseases can be prevented, but health care systems do not make the best use of their available resources to support the prevention process. All too often, health care workers fail to seize patient interactions as opportunities to inform patients about health promotion and disease prevention strategies. Furthermore, most current health care systems are

Copyright (C) 2009 Victoria University. This document has been published as part of the Journal of Business Systems, Governance and Ethics in both online and print formats. Educational and non-profit institutions are granted a nonexclusive licence to utilise this document in whole or in part for personal or classroom use without fee, provided that correct attribution and citation are made and this copyright statement is reproduced. Any other usage is prohibited without the express permission of the based on responding to acute problems, urgent needs of patients, and pressing concerns. The hallmarks of contemporary health care are testing, diagnosing, relieving symptoms and expecting a cure. While these functions are appropriate for acute and episodic health problems, a disparity occurs when applying this model of care to the prevention and management of chronic conditions. Preventive health care is inherently different from health care for acute 
problems, and in this regard, current health care systems worldwide fall remarkably short [1].

The World Health Organisation further suggest that well-designed, locally relevant and sustainable clinical information systems (IS) are essential if the goal of coordinated long-term care is to be achieved. They enable the organization of patient information, tracking and planning of patient care, provision of support for patient self-management, and scheduling of patient follow-up. These systems are especially effective when they encourage communication between clinical team members and patients [3].

However, motivating doctors in primary care settings to implement current clinical best practice and information technology (IT) supported systematic approaches to chronic condition care has so far proven illusive [4-10].

In Australia, for example, the last few years have seen strong calls and financial incentives from the Federal Government for the application of technological advances to contain escalating health costs [11, 12]. These incentives resulted in considerable uptake of computers, but failed to translate in the actual use of those technologies for systematic care [13-18]. In short, technological and financial approaches have failed to motivate a shift in current practice. And although there at least almost fifty theories in use in the information systems field alone [19] the motivational forces that lead to successful implementation and adoption of Information systems in health settings for the prevention and management of chronic diseases in primary health care settings are not well known.

This article discusses the motivations behind the implementation of a chronic disease information system (CDIS) in a number of general practices that are part of a particular general practice network in Australia.

\title{
Literature Review
}

An important part of the discussion in this article is an examination of the different approaches to health care.

\begin{abstract}
Evidence-based medicine is a rather young concept that entered the scientific literature in the early 1990s. .... Its focus is on offering clinicians the best available evidence about the most adequate treatment for their patients. ...Patient-centered medicine, although not a new phenomenon, has recently attracted renewed attention. ... It puts a strong focus on patient participation in clinical decision making by taking into account the patients' perspective, and tuning medical care to the patients' needs and preferences.
\end{abstract}

(Bensing, 2000: 17)

Binsing (2000) goes on to add that evidence-based medicine is disease-oriented, not patient-oriented. The other major difference is that general practitioners (GPs) build capacity on the treatment of diseases by evidence from large clinical trials, not necessarily from building experience by treating patients themselves (although obviously the two are not mutually exclusive).

The advent of evidence-based medicine, as opposed to acute care models, and in particular the production of best practice clinical guidelines, has been a significant recent advance in medical practice. However, a consistent finding in health services research is the gap between the evidence and actual medical practice [20]. Studies show that 30 to $40 \%$ of patients do not receive care according to current scientific evidence, while approximately $20 \%$ of the care provided is not needed or is potentially harmful $[8,9]$. Research into the barriers to uptake of evidence identifies such barriers to be multifactorial: professional (knowledge, skills, medico-legal concerns), social (peer influence) and organisational (time constraints, complexity, financial) [21].

This premise begs the questions: what are these clinical 'shifts'? How can information systems support them? The health literature tells us that the adoption of technology-supported systematic approaches in primary (direct to patient) care require a major shift in current medical care approaches [22, 23]. 
Wagner, a prominent chronic diseases care advocate, suggests that the effective interventions tend to fall into one of five areas [24, 25]:

1. The use of evidence-based, planned care: An information systems implementation could easily provide the necessary evidence to clinicians, extracting medical data from their electronic health records (if available) in a usable form, and presenting the clinician 'evidence' for the need to alter medical treatment based on internationally valid medical protocols developed for the care of chronic disease sufferers. The planned care can easily be organised in an automated and systematic way through the use of electronic recall and reminders [26-28].

2. Reorganization of practice systems and provider roles: the use of team approaches in chronic disease information systems (CDIS) care is well documented in the health literature, providing and supporting specific roles to nurses, practice managers and administrative staff so that all make a contribution to the patient's care $[8,17,28-30]$.

3. Improved patient self-management support: CDIS can produce instant electronic management plans and supporting care-educational literature to support the patient outside the practice [27].

4. Increased access to expertise: CDIS should be able to provide easy access to referral templates for clinicians to use to refer patients to the appropriate specialist as well as ready made decision support systems for diagnosis, prevention and management of CDs [8].

5. Greater availability of clinical information: CDIS should be able to efficiently collate all the relevant clinical patient information for the clinician as required [26].

In this article we are interested in the motivations for general practices to adopt information systems that support the use of evidence-based, planned care. A discussion of the motivations is particularly crucial if we take into account that the central assumptions of the evidence-based medicine paradigm may not be shared by all general practitioners, making its application in general practice a particular challenge $[31,32]$. Some GPs regard clinical evidence as a 'square peg to fit in the round hole' of the patient's life [33]

\section{Motivational factors driving change in general practice}

The literature suggests that affecting change in any organisation is at best extremely difficult. Logical reasons for change do not appear to automatically translate into change in behaviour or practice for a variety of reasons and this is just as true in primary health care settings [7, 21, 34]. The literature also suggests that although a number of 'business' models for information systems in primary care have existed for a while, the focus of implementations has mainly been on the advantages that the technology brings to general practice. Hence, development and implementation models for general practice have been 'technology driven'; traditionally tending to see the implementation process as a technical matter removed from organizational dynamics [14]. Nevertheless, it is generally accepted that the traditional technical approaches are not adequate to understand the process of implementation of information systems [35]. There is substantial agreement that the success of implementing information systems is determined by more socio-technical factors [36-38]; even though it is less clear what these factors are [39]. This is all in addition to the difficulties that can be faced when trying to implement an evidencebased system as described in the previous section.

The following sections identify different motivators for the adoption of CDIS in general practices.

\section{Patient motivator}

As described earlier, this motivator for the adoption of CDIS is concerned with the identification of a CD care problem or evidence of a gap in care. There is growing evidence that there are serious problems with the quality of care that patients with chronic conditions receive; with some studies suggesting that only 20 to $50 \%$ of people with common chronic conditions are under adequate control [40-42]. There appears to be often little 'translation' of the problem from the world of academic research to the practice level. This is also supported by the literature where it is estimated that it can 
take up to 17 years for clinical evidence to be put into practice at the GP level [43]. Thus, the chance to introduce a system which could be seen to streamline this process would be seen as being desirable.

\section{Patient Needs motivator}

In an Australian study, GPs believed that some patients want them to take overall control of their condition, listen to and help them deal with their problems (not just treat their symptoms), educate them, and, for older patients, provide social contact. Patients also want their GP to ensure they have an adequate quality of life. GPs felt that this placed great pressure on them [30]. There are new social expectations of health care, scientific cures and technological advances [15, 44]; as well as ageing populations and less community cohesion and social support [4, 15, 45]. Even the Internet has become a challenging medium often used by patients to question GPs on possible diagnosis and treatments.

Interestingly, some GPs believe that the patient will not change their unhealthy behaviour [46]. They have described how patient compliance, motivation and capacity influence the type of care given: 'In chronic care, you need the cooperation of the patient; it's a team effort involving the practice and the patient.' Factors such as the severity of the patient's condition, his/her social situation, level of education and attitude towards the illness all need to be taken into account [30].

\section{Internal motivators}

Internal motivators are present when the push for the adoption of a CDIS is from within a practice or GP network. Typically, these motivators are based on the personal values and beliefs of GPs, since they are typically the ones to make strategic decisions at this level. At the centre of general practice is the fundamental principle of patient care. Oldroyd et al (2003), in a study of Australian GPs' perception of chronic care, found that GPs saw themselves as coordinators of care as well as advocates for patients; including educating them about their illness, helping them to understand specialist recommendations and working in partnership with them. Some GPs talked about a tension between the GP as a businessperson, the GP as a patient support and the GP as an evidence-based clinician. Some even indicated they try to avoid chronic-disease care and to dissuade prospective patients with chronic diseases from coming to the practice [30]. On the other hand, GPs also felt that chronic care was rewarding because it enabled them to get to know their patients better, they could prevent complications and their patients appreciated them and felt happier. Patients also seem to come to terms better with the seriousness of their illness [30]. Also, a GP 'business' does not subscribe to the bottom line alone. Thus, decisions about processes within the practice are also influenced by 'clinical level' strategic decisions. These are well recognised in the health literature; for example, Ralph Audehm, a well known GP, academician at Melbourne University (Australia) and clinical systems promoter, outlines a number of researched strategic questions that GPs will ask themselves to make sense of the challenges at hand. For example, some of these are (Audehm 2004):

- Is it important? (Burden of illness)

- Am I likely to be effective? (Role, impact)

- Can I make the outcome visible? (Feedback, observable/measurable)

- What will assist getting a quick return (reward/reinforcement)

- Is it desirable (win-win, all stakeholders)

- Is it doable? (Realistic)

- Can we make it a routine part of practice? (Sustainable).

These multiple 'bottom lines' must be taken into account within the motivational framework to be able to effectively motivate GPs $[15,17]$.

Another important factor to take into account is that GPs can be very wary of investing resources into their practices, and sometimes with good reason. Much of what is 'pushed on them' by external bodies (including Governments) is not necessarily of benefit to them. For example, many of the benefits of the introduction of information technology in general practice accrue to other sectors of the health system, such as hospitals and pathology companies, rather than directly to the practice [13]. 
However, GPs are not the only players to influence strategic decision making and developing awareness at the internal level, for example, 'Local champions', such as practice managers in larger practices, are an important feature of systems in the literature, who must also actively and enthusiastically promote the system, build support, overcome resistance, and ensure that the system is actually installed and used [29].

A possible key motivator for GPs might be the use of CDIS to avoid litigation caused by inefficiencies, such as ineffective recall systems (Jessee and Morgan-Williams 1987). Effective CDIS can put backup systems in place that patients are reminded about being screened for the existence of chronic conditions at suitable intervals.

In summary, internal motivators are one of the keys to creating effective awareness of the issues at the strategic level. A user of the framework must be able to understand those forces and situations to gain an insight into the practice's readiness for change.

\section{External motivators}

External motivators are present when an external body provides incentives or direction for the introduction of CDIS. The offer of financial incentives (by health authorities) for the completion of predetermined cycles of care to individual chronic disease sufferers can be important. For example, if an Australian GP performs a six month and a one year review of a diabetic patient, by way of taking certain measurements and performing certain blood tests to control the disease, the GP gets an extra amount of money on top of the normal consultation. These Practice Incentive Payments (PIPs) promote integrated delivery systems though the use of practice guidelines; preventive care interventions and disease management programs [5].

Another important external factor involves other professional bodies, which can play a determinant role in motivating practices to act on perceived shortcomings. Bodies like the Australian General Practice Accreditation Limited (AGPAL) are providers of quality improvement that support primary care practice teams to increase efficiency, reduce risk and stay current with trends and best practice [47]. Practices seek accreditation as a way of showing their customers (patients) that there is an appropriate standard of care at their practice.

As already suggested, government forces can also influence adoption of information systems in general practice. The Australian federal government encourages larger practices though its Link program as a means of achieving modernisation, economies of scale and co-location of health services. In 1998/99, an incentive payment to encourage mergers between small practices was introduced [48].

In Australia, General Practice Networks have been instrumental in commencing the attitudinal and cultural shifts necessary at the local level for general practitioners to comprehend the potential uses of information technology [13, 49-51]. The establishment of these networks (previously known as 'divisions of general practice') has helped to break down the historical isolation of general practitioners from other parts of the health system (and from each other). Through these networks, general practitioners are able to explore the benefits of information sharing within the context of emerging team approaches to the care of individuals and communities, and to address issues of confidentiality, privacy and consent [13].

\section{Methodology}

In order to examine the motivational factors outlined in the previous section, a case study approach has been adopted - with an Australian general practice network being the foundation of the case. This approach allows collected data to be analysed, either to build up or to validate or theories, typically through collection of textual data through interviews [52-54]. The data collection technique used in this study was primarily semi-structured interviews. In this specific instance the analysis involved a comparison of the views of 28 general practices in the network as to the motivations behind their adoption of CDIS, which were subsequently compared back to the literature. 


\section{Research approach}

This study involved a socio-technical exploratory approach to identify potential motivating factors for the adoption of CDIS via a literature review (as already identified) [55]. In this study, preliminary interviews were carried out with practice managers in 10 general practices within the general practice network region, where at least one CDIS had been used for more than three years. A second, larger data collection phase, then examined the views of different stakeholders in addition to practice managers: GPS, nurses and staff. The population characteristic of the practices and individuals tested in the study is shown in Table 1.

Table 1: Demographics of data collection

\begin{tabular}{|l|c|}
\hline Number of Practice in General Practice Network & 38 \\
\hline Number of practices examined & 28 (75\% of network) \\
\hline Number of practice managers interviewed & 13 \\
\hline Number of doctors interviewed & 10 \\
\hline Number of nurses interviewed & 6 \\
\hline General staff interviewed & 7 \\
\hline Total interviews & 36 (average 1.3 interviews per practice) \\
\hline
\end{tabular}

\section{Results}

In the preliminary data collection phase, ten practice managers were asked about their motivations for the adoption of their CDIS. In this question they were asked to rate (from 1 (important motivator) to 6 (lowest motivation):

- One patient care gap motivator (patient care)

- Three internal motivators (risk management, insurance to minimise risks and involving staff), and

- Four external motivators (the support of the general practice network, the need to be accredited, general government influence and financial incentives for adoption).

The average ratings of their responses are shown in Table 2.

Table 2: Ratings for CDIS motivators

\begin{tabular}{|l|l|c|}
\hline Motivator & Classification & Average Rating \\
\hline Patient care & Patient needs & 1.67 \\
\hline Risk management & Internal motivator & 2.00 \\
\hline General practice network support & External motivator & 3.56 \\
\hline Accreditation issues & External motivator & 4.33 \\
\hline Wanted to involve/ include staff & Internal motivator & 4.78 \\
\hline Financial incentive (PIP) & External motivator & 5.22 \\
\hline Government influence & External motivator & 5.67 \\
\hline Insurance incentive (to minimise risk) & Internal motivator & 5.78 \\
\hline
\end{tabular}

The two clear motivators from the preliminary phase of the study were patient care (the one "patient needs' motivator listed) and the need for risk management (an internal motivator). The other factor considered (on average) to at least be of 'some importance' was support by the general practice network itself. It was interesting to the authors that, even though practice managers were not GPs, they still rated patient care so highly even though they were generally employed to manage the 'business' side of the practice.

In the main data collection stage, further interviews were conducted and the different stakeholders were asked again rate the different motivations for adopting CDIS. All of the other categories of stakeholders (GPs, nurses and general staff) rated patient care as the most important motivation. Different reasons for ranking patient care. For instance, one GP suggested that it is embedded in the practice:

My first ranking would patient care because it was fragmented and buried within the practice... so that's number one. 
Another GP suggested that patient care is rated so highly because:

... what you're trying to do is do the best for your patient with chronic condition...

Once again, the second highest rated response was Risk Management. This comment from a GP highlights the possible threat of litigation.

I don't really recall that our practice took a different view on more assertive Cervical Screening than it took to more assertive CD management in general. Maybe conversely if there was a driver it was owning our own recall systems, the driver was the Medical defence industry and MDAV in particular and their risk management programs highlighting cervical screening systems as being one of the more evident causes of medical litigation.

At this point it could possibly be argued that 'risk management' actually is an external motivator - as the threat of litigation does come from outside of the practice.

After the main data collection occurred, financial incentives rated higher overall than it did just for practice managers. One GP actually rated financial incentives higher than patient care. It was also rated highest by a practice manager. One general staff member commented:

Financial of course, they are Doctors aren't they?

The need for accreditation was the next highest rated motivation.

However, some of the comments suggested that the task of rating or ranking the motivations is not quite as simple as it might seem. Here, although a GP rated patient care as the most important factor, there is a rider...

Number one is patient care, I mean...it has to be a good idea and it has to be plainly demonstratively good for the patient, there is no point in doing anything if it is not good for the patient, in conjunction to that it has to be of benefit to me...taking on a new initiative costs me a bucket of money and not be rewarded I am not going to do it.

These comments from a GP and a nurse highlight the interrelationships:

I guess back then it was driven by risk management issues, financial incentives, which gets back to accreditation but then all integrates into patient care but I think you have got to be convinced that something is worth doing and basic things like these are worth doing

I think it's a bit of each (on the list of motivators) For me... from my point ...of the clinic, I think we need consistency, so that if the patient sees one doctor and then see another doctor we can be more consistent...sure for accreditation purposes we want to keep our information up-to-date, but I think we really need to make sure we're screening...I think we need get them all so we can treat them to the best of our ability and make sure they're getting the best of care... and if we do it across the board so everyone... (gets the care)

In summary, the data collected suggests that the motivational forces tend to be inter-related. However, a much higher influence is asserted by patient care. This was well supported across all practice types and different stakeholders. However, interviewees were very clear to point out that patient care must conform to financially sustainable models and be facilitated by workforce and infrastructure factors.

There are two points to make here: one is that an approach to implementing a chronic disease information system in general practice must be able to tap into these motivational forces as a complete solution, catering to the perceived needs of stakeholders. The second is that evidence based analysis is crucial to create awareness in individuals of the 'gaps' in care affecting chronic disease patients.

\section{Conclusion}

This article identified different categories of motivators and a defined ranking of their strength to affect the adoption of Chronic Disease Information systems in general practice. Following a literature review 
of known motivators, thirty-six participants (representing, doctors, nurse, practice managers and staff) from twenty-eight practices were interviewed to examine the relevance of these factors. The findings suggested that the key, and highest ranked, motivational factor identified in this study for the adoption of CDIS was gaps in patient care (Patient Care) as a motivational force. However, another important factor that rated highly in the study was the need to introduce CDIS as a means of minimising the risk of legal threats (risk management), predominantly as a means of avoiding patient litigation. Other prominent motivations for the introduction of CDIS were the benefits of financial incentives and increased likelihood of gaining or maintaining accreditation with accreditation bodies. Another important finding was the need to consider the relationship between these motivational forces when adopting CDIS. For instance, even if CDIS is adopted for the purpose of improving patient outcomes, it should still be done so in an environment that allows for improved financial outcomes, or at least no deterioration of the financial situation.

In essence, any information systems implementation would be better accepted if the main drivers or motivators are understood before the implementation takes place; and the implementation itself caters for their solutions as part of the overall system. Furthermore, no single motivator should be seen to be the only driver, a multi-pronged approach that strengthens all identified motivators equally should be used to satisfy the multiple needs of those affected by the introduction.

\section{References}

Aarts, J., Doorewaard, H. and Berg, M. (2004). "Understanding Implementation: The Case of a Computerized Physician Order Entry System in a Large Dutch University Medical Center." J Am Med Inform Assoc 11(3): 207-216.

AGPAL. (2005). "Home Page.” Retrieved 17-July, 2005, from http://www.qip.com.au/company.asp.

Ahmadi, M. and Brabston, M. (1997-1998). "MIS Education: Differences in Academic Practice and Business Managers Expectations.” Journal of Computer Information Systems Winter: 18-25.

AIHW (2006). Chronic disease and associated risk factors in Australia, 2006. Camberra, Australian Government, Department of Health and Ageing.

Alter, S. (1999). Information Systems: A Management Perspective. Reading, MA, Addison-Wesley.

Ash, J. (1997). "Organizational factors that influence information technology diffusion in academic health sciences centers." J Am Med Inform Assoc. 4(2): 102-11.

Australian Institute of Health and Welfare (2004). National public health expenditure report 2000-01. Canberra.

Awang, F. (2002). A Comparative Analysis of the Workplace and Technology Skills Needed by Entry-Level Information Systems Graduates as Perceived by Illinois Fortune 500 Human Resource Managers and Illinois Information Systems Educators. Department of Workforce Education and Development, . Carbondale, Southern Illinois University: 154.

Balas, E. A. and Boren, S. A. (2000). Managing clinical knowledge for health care improvement. Yearbook of Medical Informatics 2000: Patient-Centered Systems. Stuttgart, Germany, Schattauer.

Benamati, J. S. and Mahaney, R. C. (2007). Current and future entry-level IT workforce needs in organizations. Proceedings of the 2007 ACM SIGMIS CPR conference on 2007 computer personnel doctoral consortium and research conference: The global information technology workforce St. Louis, Missouri, USA, ACM Press.

Bodenheimer, T. (1999). "The American health care system; the movement for improved quality in health care." N Engl J Med 340: 488-492.

Braun, G. F., Tesch, D. B. and Skeldon, R. (2004). The Student-Professor Research Relationship: Examining IS Employer Skills Expectations. The Proceedings of ISECON 2004(Also appears in Information Systems Education Journal 3: (42). ISSN: 1545-679X.), Newport.

Burns, R. (1990). Introduction to research methods. Australia, Longman.

Caputo, D., Kovacs, P. and Turchek, J. (2004). Defining the Essential Skill and Functional Areas of Study in Information Technology as Measured by a Survey of Field Professionals. ISECON 2004, Newport.

Case, T., L., Price, B. A. and Rogers, C. F. (1997). The Information Systems Industry: What Abilities Does it Want From Its New Hires? A Look at the Southeastern U.S. Proceedings of the International Academy for Information Management. 
Chew, M. and Van Der Weyden, M. (2003). "Chronic Illness: The burden and the dream.” EMJA 179(5): 229230.

Ching, R. K. H., Glorfeld, L. W. and Lam, M. (2000). Integrating the IT/IS Professional Community with IT/IS Academic Programs. Sixth Americas Conference on Information Systems.

Chrysler, E. and van Auken, S. (2002 (Spring)). "Entry Level Value Versus Career Value of MIS Courses: Faculty Expectations Versus Alumni Perceptions.” Journal of Computer Information Systems 42(3): $38-43$.

Coiera, E. (2004). "Four myths about the information revolution in healthcare." Retrieved October 2004, 2004, from http://www.coiera.com/papers/ippr/ippr.htm.

Comley, P. (1996). The use of the Internet as a data collection method. Proceedings of the ESOMAR/EMAC Symposium on Research.

Department of General Practice (2001). The relative effectiveness of population health intervention in the General Practice setting. University of Melbourne, Commonwealth Department of Health and Ageing.

Department of Health and Aged Care. (2003). "Practice Incentive Payments." Retrieved November, 2003, from http//: www.health.gov.au/pip/index htn.

Department of Health and Ageing (2004). Divisions of General Practice: Future Directions Government Response to the report of the review of the role of Divisions of general Practice. Camberra, DoHA.

Department of Health and Ageing. (2005). "Divisions of General practice Program." Retrieved 9 June, 2005 , from http://www health.gov.au/internet/wcms/publishing nsf/.

Dixon, R. and Turner, R. (2006). Electronic vs. Conventional Surveys. Handbook of Research on Electronic Surveys and Measurements. Reynolds, R. Herschey PA, IDEA: 416.

Fang, X., Lee, S. and Koh, S. (2005). "TRANSITION OF KNOWLEDGE/SKILLS REQUIREMENT FOR ENTRY-LEVEL IS PROFESSIONALS: AN EXPLORATORY STUDY BASED ON RECRUITERS' PERCEPTION." Journal of Computer Information Systems 46(1): 58-70.

Fang, X., Lee, S., Lee, T. E. and Huang, W. (2004). "Critical Factors Affecting Job Offers for New MIS Graduates.” Journal of Information Systems Education 15(2): 189-204.

Freeman, A. C. and Sweeney, K. (2001). "Why general practitioners do not implement evidence: qualitative study. ." BMJ 323(7321): 1100-2.

Goles, T. (2001). A View from the Entry Level:Student Perceptions of Critical Information Systems Job Attributes. SIGCPR 2001, San Diego CA.

Grimshaw, J., Thomas, R., Maclennan, G. and et al (2004). "Effectiveness and efficiency of guideline dissemination and implementation strategies." Health Technol Assess.

Grol et al (1998). "Attributes of clinical guidelines that influence use of guidelines in general practice: Observational study." BMJ : British medical journal 315: 418-421.

Grol, R. and Grimshaw, J. (2003 ). "From best evidence to best practice: effective implementation of change." Lancet 362: 1225-1230.

Gross, P. F., Leeder, S. R. and Lewis, M. J. (2003). "Australia confronts the challenge of chronic disease.” MJA 179(5): 233-234.

Hagan, D. (2004). Employer Satisfaction with ICT Graduates. Sixth Australasian Computer Education Conference (ACE2004). Conferences in Research and Practice in Information Technology, Australian Computer Society.

Haywood, E. and Madden, J. (2000). Computer Technology Students - What skills do they really need? ACE 2000, Melbourne, Australia.

Health Insurance Commission (2002). Contract between Commonwealth and Divisions of General Practice for the Implementation of the 2001 Federal Budget,. HIC: 17-18.

Health Insurance Commission. (2003). "Practice Incentive Payments." Retrieved November, 2003, from http//: www hic.gov.au/pip.htm.

HealthConnectSA (2007). GP Change Management Strategy: Engagement with General Practice, South Australian Department of Health.

Institute of Medicine (2001). Crossing the Quality Chasm: A new health System for the 21st Century. Washington DC, National Accdemy Press.

Jack, L., Jr, Boseman, L. and Vinicor, F. (2004). "Aging Americans and diabetes. A public health and clinical response." Geriatrics 59(4): 14-17.

Janicki, T., Kline, D., Gowan, J. A. and Konopaske, R. (2004). "Matching Employer Needs With IS Curriculum: An Exploratory Study.” Information Systems Education Journal 2(21): 3-19.

Kearley K., Freeman G. and Health A. (2001). "An exploration on the value of the personal doctor-patient relationship in general practice." British Journal of General Practice 51(9): 712-718. 
Kim, Y., Hsu, J. and Stern, M. (2006). “An Update on the IS/IT Skills Gap.” Journal of Information Systems Education 17(4): 395-402.

Landry, J. P., Longenecker, H. E., Haigood, B. and Feinstein, D. L. (2000). Comparing Entry-Level Skill Depths Across Information Systems Job Types: Perceptions of IS Faculty. Sixth Americas Conference on Information Systems, Long Beach, CA.

Lang, T. R., Raver, R. A., White, J. A., Hogarty, K. Y. and Kromrey, J. D. (2000). Survey Data Collection Strategies:Response Differences Between Web-based and Paper-based Methods. Annual meeting of the Florida Educational Research Association,, Tallahassee, Florida.

Latham, A. (2000). "Matching Graduates with Organisational Needs.” Retrieved 17/7/2000, from http://www.comp.glam.ac.uk/ukais2000/UKAISpaps.htm.

Lee, P. C. B. (2006). "Information Technology Professionals' Skill Requirements in Hong Kong." Contemporary Management Research 2(2): 141-152.

Lee, S., Kohb, S., Yena, D. and Tang, H.-L. (2002). "Perception gaps between IS academics and IS practitioners: an exploratory study." Information \& Management 40(1): 51.

Leonard, L. (1999). "Survey shows skills gap still a problem.” Retrieved 23/6/2002, 2002, from http://www.itac.ca/.

Liaw, T. and Humphreys, J. (2006). "Rural eHealth paradox: It's not just geography!" Aust J. Rural Health 14: 95-98.

Lippert, S. and Anandarajan, M. (2004). "Academic vs. practitioner systems planning and analysis.” Communications of the ACM 47(9): 91-94.

Littlejohns, P., Wyatt, J. C. and Garvican, L. (2003). "Evaluating computerised health information systems: hard lessons still to be learnt." BMJ : British medical journal(326): 860-863.

Lorenzi, N. M. (2004). "Beyond the gadgets: Non-technological barriers to information systems need to be overcome too." BMJ : British medical journal 328: 1146-1147.

Mawhinney, C. H., Morrell, J. S., Morris, G. J. and Munro, S. R. (1999). Updating the IS Curriculum: Faculty perceptions of industry needs. Special Interest Group on Computer Personnel Research Annual Conference, New Orleans, LA, ACM.

Medlin, B. D., Dave, D. S. and Vannoy, S. A. (2001). "STUDENTS' VIEWS OF THE IMPORTANCE OF TECHNICAL AND NON-TECHNICAL SKILLS FOR SUCCESSFUL IT PROFESSIONALS." Journal of Computer Information Systems 42(1): 65-69.

Mehta, R. and Sivadas, E. (1995). "Comparing response rates and response content in mail vs email surveys." Journal of the Market Research Society. 37(4): 429-439.

Miller, R. and Luse, D. (2004). "Advancing the IS curricula: The identification of important communication skills needed by IS staff during systems development." Journal of Information Technology Education 3: $117-131$.

Miller, R. and Spurlock, A. (2000). The importance of communication skills: Perceptions of IS professionals, IS managers, and users, LOUISIANA TECH UNIVERSITY.

Mitchell, M. A. and McAIum, H. G. (1999). "Skill Set for Success of New Business School Graduates: Do Prospective Employers and University Faculty Agree?" Journal of Educatin for Business(September/October): 33.

Mittman, R. (2004). Using Clinical Information in Chronic Disease Care: Expert Workshop Summary, California HealthCare Foundation.

Mumford, E. (2006). "The Story of Socio-Technical Design: Reflections on its Successes, Failures and Potential." Information Systems Journal 16(4): 317 - 342.

Nabi, G. R. and Bagley, D. (1999). “Graduates' perceptions of transferable personal skills.” Education + Training 41(4): 184-193.

Nader, C. (2007). Expert warn of a health 'tsunami'. The Age. Melbourne.

Nereu, F., Kock, N. F., McQueen, R. J. and Scott, J. L. (2000). "Can Action Research be Made More Rigorous in a Positivist Sense? The Contribution of An Iterative Approach." Action Research E-Reports 9.

Noyes, J. and Baber, C. (c1999). User-centred design of systems. Berlin ; London :, Springer-Verlag,.

Oldroyd, J., J. Proudfoot, F. Infante, G. Davies, T. Bubner, Chris Holton, J. Beilby and Harris, M. ( 2003). "Providing healthcare for people with chronic illness: the views of Australian GPs." MJA 179(1): 3033.

Price, B. A. and Randall, C. H. (2004). Technology-based degrees: do faculty and students agree on necessary skills for success in these programs? CITC5 '04 Proceedings of the 5th Conference on information Technology Education, Salt Lake City, UT, USA, ACM Press, New York, NY.

Randall, C. H. and Price, B. A. (2006). "Desirable attributes for computing graduates: is there agreement?." SIGCSE Bull 38(2): 91-96. 
Richards, B., Bolton, P., Veale, B. and Quinlan, F. (1999). Information Technology in General Practice: A monograph commissioned by the general practice branch of the Commonwealth Department of health and Ageing, Commonwealth Department of health and Ageing.

Rust, G. and Cooper, L. A. (2007). "How Can Practice-based Research Contribute to the Elimination of Health Disparities?" The Journal of the American Board of Family Medicine 20(2): 105-114.

Schenk, K. D. and Pick, J. B. (1998). “A framework for successful partnerships between industry and academia." Journal of Computer Information Systems Fall: 65-71.

Schneberger, S. and Wade, M. (2006). Theories Used in IS Research Reference Library.

Schuster, D. M., MD, S. E. H., MD, C. B. C., MSN, CAC, Debra S. Swayngim, RHIA, CAC and Keith Y. Kohatsu, M. (2003). "Involving Users in the Implementation of an Imaging Order Entry System." American Medical Informatics Association 10(4): 315-321.

Skidmore, S. and Eva, M. (2004). Introducing System Development. New York, Palgrave McMillan.

Smith, E. W. (1998). "How to Identify "Soft” Skills in IT/IS/MIS Management Candidates." Retrieved 11/7/2000, from http://www.ittalent.com.softskills.htm.

Snoke, R. and Underwood, A. (2000). Generic Attributes of IS Graduates - A Comparison of Australian Industry and Academic Views. PACIS 2000.

Snoke, R. and Underwood, A. (2002). Generic Attributes of IS Graduates - A Comparison of Australian Industry and Academic Views. Eighth Americas Conference on Information Systems, AIS.

Solberg, L. (2003). "The KISS Principle in Family Practice: Keep it Simple and Systemstic." Family Practice Management.

Stahl, B. C. (2007). "ETHICS, Morality and Critique: An Essay on Enid Mumford's

Socio-Technical Approach." Journal of the Association for Information Systems 8(9): 479-490.

Sturnberg, J., Martin, C. and Pittman, L. (2003). "Rethinking general practice for the 21 st century: The patient counts!" Australian Family Physician 32(12): 1028-1031.

Tang, H.-L., Lee, S. and Koh, S. (2000-2001). "Educational gaps as perceived by IS educators: A survey of knowledge and skill requirements." Journal of Computer Information Systems 41(2): 76-84.

Tesch, D. B., Braun, G. F. and Crable, E. A. (2002). Alumni Assessment of the 1990s MIS Curriculum at a Liberal Arts University. ISECON 2002.

Tomlin, Z., Humphrey, C. and Rogers, S. (1999). "General practitioners' perceptions of effective health care." BMJ 318(7197): 1532-5.

Trauth, E. M. and Farwell, D. W. (1993). “The IS expectation gap: Industry expectations versus academic preparation.” MIS Quarterly 17(3): 293.

Turner, R. and Lowry, G. (1999). Educating Information Systems Professionals: Towards a Rapprochement Between New Graduates and Employers. Tenth Australasian Conference in Information Systems, Wellington, NZ, ACIS.

Van Der Weyden, M. B. (2003). “Australian general practice: time for renewed purpose.” MJA 179(1): 6-7.

Van Slyke, C., Kittner, M. and Cheney, P. (1997). "Skill Requirements for Entry-Level IS Graduates: A Preliminary Report from Industry." Retrieved 26/4/2000, from http://groucho.bsn.usf.edu/ vanslyke/isecon $1 \mathrm{htm}$.

Veale, B. M. (2003). "Meeting the challenge of chronic illness in general practice." MJA 179(5): 247-249.

Wagner, E. (2000). "The role of patient care teams in chronic disease management." BMJ : British medical journal 320: 569-572.

Wagner, E. H., Austin, B. T. and Korff, M. V. (1996). "Organizing Care for Patients with Chronic Illness “ The Milbank Quarterly 74(4): 511-544.

Ward, J. E., J. Gordon, et al., (1991). "Strategies to increase preventive care in general practice." MJA 154(8): 523-526.

Weber, J. E., McIntyre, V. J. and Schmidt, M. (2001). "Explaining IS Student and IS Industry Differences in Perceptions of Skill Importance.” Journal of Computer Information Systems 41( 4 (Summer)): 79-84.

White, B. (2000). "Using Flow Sheets to Improve Diabetes Care." Retrieved May 27, 2004, from http://www.aafp.org/fpm/20000600/60usin html.

WHO. (2008a). “Chronic diseases.” Retrieved January 8, 2008, from http://www.who.int/topics/chronic diseases/en/.

WHO. (2008b, 15 June 2007). “Integrating prevention into health care.” Retrieved January 7, 2008, from http://www.who.int/mediacentre/factsheets/fs172/en/index.html.

WHO. (2008c). "Use of patient information systems." Chronic diseases and health promotion Retrieved January 8, 2008, from http://www.who.int/chp/chronic disease report/part3 ch2/en/index13.html. 
Williams, P. A. (1998). Employability Skills in the Undergraduate Business. Curriculum and Job Market Preparedness: Perceptions of Faculty and Final-Year Students in Five Tertiary Institutions., Andrews University.

Wooldridge, M. (1998). Health Budget Statement. Camberra, DHAC.

Woratscheck, C. R. and Lenox, T. L. (2002). Information Systems Entry-Level Job Skills: A Survey of Employers. ISECON 2002.

Yin, R. K. (2003). Case Study Research. Thousand oaks, California, SAGE.

Young, D. (1996). "The Relative Importance of Technical and Interpersonal Skills for New Information Systems Personnel.” Journal of Computer Information Systems(Summer): 66-71. 